\title{
Jellyfish as an alternative source of food for opportunistic fishes
}

\author{
Marques Raquel ${ }^{1,2^{*}}$, Bouvier Corinne ${ }^{1}$, Darnaude Audrey M. ${ }^{1}$, Molinero Juan-Carlos ${ }^{3}$, \\ Przybyla Cyrille ${ }^{4}$, Soriano Solenn ${ }^{5}$, Tomasini Jean-Antoine ${ }^{1}$, Bonnet Delphine ${ }^{1}$
}

${ }^{1}$ Laboratoire MARBEC, Université de Montpellier, CC093, Place Eugène Bataillon, 34095 Montpellier Cedex 05, France

${ }^{2}$ Faculdade de Ciências e Tecnologia, Universidade do Algarve, Campus de Gambelas, 8005-139

Faro, Portugal

${ }^{3}$ GEOMAR - Helmholtz Centre for Ocean Research Kiel, Marine Ecology/food webs, Duesternbrooker Weg 20, D-24105 Kiel, Germany

${ }^{4}$ Ifremer, Unité Biologie des Organismes Marins Exploités, UMR 5119 Ecosym, Chemin de Maguelone, 34250 Palavas Les Flots, France

${ }^{5}$ Université de Montpellier, Station Méditerranéenne de l'Environnement Littoral, 2 Rue des Chantiers, 34200 Sète, France

*Corresponding author : Raquel Marques, marques.rfs@gmail.com

\begin{abstract}
:
Although scientific interest on jellyfish ecology has substantially increased in the last decades, little is known on the role of potential predators shaping their population dynamics. Jellyfish were long considered as 'dead ends' within food webs, and therefore overlooked as potential food source for higher trophic levels, e.g. fishes. Here this question is tackled by using comprehensive laboratory experiments assessing fish predation on jellyfish. The approach included all the life stages (polyps, ephyrae and medusa) of Aurelia sp. versus more traditional aquaculture feeds in an easily farmed opportunistic fish, the gilthead seabream Sparus aurata (L.). Results revealed that all life stages of Aurelia sp. were accepted as a source of food by $S$. aurata, whose grazing pressure varies depending on the jellyfish life stage. Higher ingestion rates were observed on young stages (i.e. small medusa) indicating their higher vulnerability to fish predation and the potential negative impact this may have on Aurelia sp. population dynamics. These results provide new insights on the so far underestimated role fish predation can have on jellyfish population dynamics. In particular, opportunistic fish species, such as $S$. aurata may contribute to control jellyfish blooms, through top-down regulations of jellyfish biomass.
\end{abstract}




\section{Highlights}

- During bloom events, jellyfish might be a source of food for opportunistic fishes. All life stages of Aurelia sp. are used as a source of food by Sparus aurata. Higher ingestion rates of fish predation were observed on Aurelia sp. young stages. Opportunistic fish species might contribute to control jellyfish blooms.

Keywords : Aurelia sp., Predation, Fish, Sparus aurata, Ingestion rate, Energy pathways 


\section{Introduction}

Jellyfish are ubiquitous components of marine food webs and acknowledged indicators of ecosystem change (Richardson et al., 2009). In recent decades, however, recurrent massive proliferations in temperate coastal waters (Brotz et al., 2012) warned on dramatic consequences for the management of ecosystem assets, including fisheries and tourism industries. Underlying mechanisms of jellyfish proliferations have been ascribed to climate changes and anthropogenic disturbances in the marine environment, i. e. mainly habitat modification and overfishing (Purcell, 2012; Richardson et al., 2009). In addition, while high human population densities persist expanding in coastal areas, the resulting anthropogenic stress continue fostering favorable conditions for jellyfish, thereby challenging the sustainable management of coastal resources (Pauly et al., 2009; Purcell et al., 2007; Purcell, 2012; Richardson et al., 2009).

Research on jellyfish ecology has long focused on bloom drivers (e.g. Purcell, 2005). However, little is known in regards to causes impairing blooms, i.e. jelly fish mortality (Purcell and Arai, 2001), which is fundamental to understand their population dynamics. In particular, jellyfish mortality during early life stages may have a major effect on population recruitment, and subsequently on adults density (Lucas, 2001). For instance, recent findings provided new insights on the role predation on polyps and ephyrae may have on jellyfish outbreaks through enhancing jellyfish mortality (e.g. Ishii et al., 2004; Takao et al., 2014).

Over decades, jellyfish were described as 'dead ends' in marine food webs, because of their high water content and low nutritional value (e.g. 2.3-3.6 KJ.g.dry $\operatorname{mass}^{-1}$ for A. aurita, Doyle et al., 2007), although gelatinous organisms are often reported in lists of fish stomachs contents. For instance, some species, such as moon fish (Mola mola) and butterfish (Peprilus triacanthus), are known to prey exclusively 
on gelatinous zooplankton (Arai, 2005, 1988; Ates, 1988; Mianzan et al, 1996; Purcell and Arai, 2001). Also, in periods of massive proliferation, jellyfish are further suggested as a non-negligible source of energy for fishes (Arai, 2005; Arai et al., 2003; Cardona et al., 2012), however quantitative estimations on the impact of fish predation on jelly fish are rare (Cardona et al., 2012; Milisenda et al., 2014). Hence, to date the strength of the trophic linkage between fish and jellyfish is barely known.

This study sought to examine the trophic relationship between fish and jellyfish. To tackle this question laboratory experiments were performed to explore the intensity of predation of coastal harvested fish species on jellyfish. The jellyfish Aurelia sp. was used as prey model and Sparus aurata as predator. The main aim was to assess predation on different life stages of Aurelia sp., and their respective attractiveness as food sources, when compared to prey types used in aquaculture. Therefore, it was intended to answer three main questions: i) What is the ingestion rate of jellyfish prey?; ii) Is the ingestion of jellyfish prey items fostered by their high availability/concentration?; iii) Are jellyfish positively selected? The approach provides evidence that jellyfish are more important as food source for fish than previously thought.

\section{Materials and Methods}

The potential fish predation on jellyfish was investigated in laboratory conditions, bearing in mind the natural conditions occurring in the Thau lagoon, NW Mediterranean, $43^{\circ} 23^{\prime} 59.10^{\prime \prime} \mathrm{N} ; 3^{\circ} 36^{\prime} 37.15^{\prime \prime}$ E. This is a semi-enclosed brackish lagoon, which harbors a resident population of Aurelia sp. (Bonnet et al., 2012; Marques et al., 2015b), providing an ideal framework to understand the links between jellyfish and fish. 
The gilthead seabream (Sparus aurata) is a common species in the northwestern Mediterranean and the main target of commercial fishery in Thau lagoon, representing at times up to $56.6 \%$ of total annual 'capéchade' catches (the most common fishing gear in Thau lagoon) (Crespi, 2002). Irrespective of age, most of gilthead seabream spend winter months at sea, where spawning occurs, and return to coastal lagoons around April (Audouin, 1962; Mercier et al., 2012). Although some adults spend significant amount of time in coastal lagoons (Mercier et al., 2012), in Thau Lagoon the population of $S$. aurata is composed mainly by juveniles under maturity age $(2-3$ years, $27-33 \mathrm{~cm}$ length; Lasserre, 1974 in Crespi, 2002). Moreover, gilthead seabream has been raised for decades in aquaculture farms worldwide and its life history is therefore well known (e.g. Moretti et al., 1999). All these criteria made it a particularly good candidate to obtain homogeneous groups of individuals with similar size.

The experiments were performed at the IFREMER institute (Institut Français de Recherche pour l'Exploitation de la Mer) in the research station of Palavas-les-Flots (France), from April to June 2014. A total of 433 S. aurata were obtained from the 'Les Poissons du Soleil' aquaculture farm. Two size classes were used in the experiments: 370 small individuals (Small Fish - SF: W of ca. $70 \mathrm{~g}$; TL= 14-19 cm), and 63 large individuals (Large Fish - LF: W of ca. $200 \mathrm{~g}$; $\mathrm{TL}=20-25 \mathrm{~cm}$ ). Fishes were acclimated in three $1500 \mathrm{~L}$ tanks filled with filtered sea water at $20-22^{\circ} \mathrm{C}$. Every two days, fishes were fed with commercial dry pellet food for sea bream (B-Nature, Le Gouessant) at $1 \%$ of the fish biomass to meet their food requirements.

The predation on various prey items was compared. All preys were kept at $20 \pm 0.5^{\circ} \mathrm{C}$. Live Artemia with about $1 \mathrm{~cm}$ length were collected in soft flats in Le Graudu-Roi and maintained in $60 \mathrm{~L}$ tank with air supply. Live Aurelia sp. ephyrae and small medusae $(\varnothing 1 \mathrm{~cm})$ were obtained from 'Jellyfish Concept' company (Cherbourg, 
France) and maintained in 15 L containers with air supply, fed with newly hatched Artemia. Medium and large Aurelia sp. medusae (Ø 4 and 7-8 cm, respectively) and colonies of Aurelia sp. polyps were collected in Thau Lagoon. Medium and large medusae were collected with hand nets, while polyps, fixed on oyster or mussel shells, were collected by SCUBA divers. They were all maintained in $60 \mathrm{~L}$ tanks with air supply.

The experiment set up was composed by 24 separate tanks of $60 \mathrm{~L}$ ( $40 \mathrm{~L}$ of sea water) with shared water and air supply, which ensure identical temperature and salinity in all tanks. Experiments were performed at $20 \pm 0.5^{\circ} \mathrm{C}$, since it is within the optimum temperature range for $S$. aurata (Feidantsis et al., 2009) and it also corresponds to temperatures at which blooms of Aurelia sp. occur in Thau lagoon (Bonnet et al., 2012; Marques et al., 2015a). Photoperiod was determined according to field conditions at the time of experiment ( $13 \mathrm{~h}$ of light and $11 \mathrm{~h}$ of dark period). As the maximum fish biomass recommended in $S$. aurata aquaculture farms is of $7 \mathrm{~kg} \cdot \mathrm{m}^{-3}$ (C. Pryzbyla pers. comm.), all experiments were performed with three SF or two LF per tank. Before each experiment, fishes were acclimated for four days in experimental tanks and maintained in starvation to ensure that all individuals empty their stomachs.

This study consisted in three different experiments, using three replicates for each treatment, the monospecific diets, the gradient of concentration and the selectivity experiments (Table 1).

\subsection{Monospecific diets}

The main goal of the monospecific diets experiment was to compare S. aurata ingestion rates for the various life stages of Aurelia sp. (polyps, ephyrae and different sizes of medusae) with those for other types of food, live or not. As $S$. aurata were acquired from aquaculture farms, dry pellets were used as control, since fishes were 
151

152

previously reared with this diet. As the carbon content or dry weight of the prey items was not determined, the comparison of the different prey items was performed according to the concentration of prey per tank (item.tank ${ }^{-1}$ ). Additionally, small, medium and large medusae were also compared according to their weight, determined according to theoretical calculations (Uye and Shimauchi, 2005).

The concentration of prey items in each treatment was calculated in order to meet $1 \%$ of fish biomass of dry pellets in each tank. Therefore, in SF and LF treatments, 44 and 80 pellets.tank ${ }^{-1}$ were used, respectively. The same concentrations were then used for Artemia and ephyrae, since they have equivalent dimensions $(0.7-1 \mathrm{~cm})$.

As small, medium and large medusae have considerably higher dimensions as pellets, Artemia and ephyrae, these prey items were provided at lower concentrations: 50 and 1 prey item.tank ${ }^{-1}$ of small and medium medusae, respectively. Large medusa was provided at the minimum possible concentration (1 prey item.tank $\left.{ }^{-1}\right)$.

In order to mimic field conditions, one colony of polyps settled on oyster shell was provided. Consequently, the initial concentration of this prey item was not artificially fixed.

\subsection{Gradient of concentration}

The goal of the gradient of concentration experiment was to assess whether Aurelia sp. ingestion could be proportional to its availability in the field. Based on the results of the first feeding experiment, small medusae $(\varnothing=1 \mathrm{~cm})$ were used for this test, using six different treatments (with initial concentrations of 5, 10, 15, 30, 40 and 50 item $\operatorname{tank}^{-1}$ ) for both size classes of S. aurata. 


\subsection{Selectivity experiment}

Selectivity experiments allowed the assessment of the influence of simultaneous availability of high nutritional quality prey (crustacean) on the potential ingestion of early life stages of Aurelia sp.. Therefore, two composite diets were supplied for both SF and LF. Diet 1 was composed by ephyrae and Artemia with equal initial concentrations, while diet 2 was composed by polyps and Artemia (Table 1). Total prey concentrations were determined as previously described in monospecific diets experiment section and equally distributed by the prey items (i.e. $0.5 \%$ for ephyrae and

\section{Artemia)}

The experiments were run for $2 \mathrm{~h}$ for all treatments, which is in accordance with previous laboratory experiments on fish predation on jellyfish (Arai et al., 2003) and allow an accurate estimation of ingestion rates, as further confirmed by a preliminary test. Since the experiment time was short, control experiment to determine prey mortality by predation from polyps/ephyrae was not required.

Prey items in each case were counted before and after the experiments, either by direct visual observation (for larger medusae) or under a dissecting microscope after filtering the water of the entire tank on a $200 \mu \mathrm{m}$ mesh sieve. Polyps attached to oyster or mussel shells were photographed with a Cannon PowerShot G16 camera at the beginning and end of the experiment. Photographs were pre-treated with Adobe Photoshop CS2 Version 9.0, in order to improve contrast and polyps were counted by eye observation. In the end of the experiments, fishes were measured and weighted.

\subsection{Calculations}

Ingestion rate per gram of fish $\left(I\right.$; prey item. $\mathrm{g}^{-1}$ fish. $\left.\mathrm{h}^{-1}\right)$ was calculated according to the equation: 


$$
I=((C i-C f) / t \cdot n) / m
$$

Where $C i$ and $C f$ are the initial and final concentration (prey item. $\operatorname{tank}^{-1}$ ) of prey in the water, respectively, $t$ is the experiment duration (h), $n$ is the number of fish in each experimental tank and $m$ is the weight of each fish $(\mathrm{g})$. The results are presented as the mean $I$ of each treatment (i.e. three replicates).

Ingestion rates of small, medium and large medusae were also compared according to their wet weight. Medusa biomass (wet weight; $W W$ ) was calculated based on medusa bell diameter $(B D ; \mathrm{cm})$, according to the equation of Uye and Shimauchi (2005):

$$
W W=0.0748 B D^{2.86}
$$

Corresponding ingestion rates in biomass $\left(\mathrm{Im} ; \mathrm{g} \cdot \mathrm{g}^{-1} \mathrm{fish} \cdot \mathrm{h}^{-1}\right)$ were calculated, according to the equation:

$$
\operatorname{Im}=I^{*} W W
$$

The results are presented as the mean $I m$ for each treatment (i.e. three replicates).

\subsection{Statistical analysis}

In monospecific diets experiments, differences in $S$. aurata ingestion rates among prey types were tested by Kruskal-Wallis test, followed by post hoc multiple comparison test by Dunn test, with Bonferroni correction $(\alpha<0.0018)$. The test of hypotheses explaining the $S$. aurata ingestion rates during the gradient of concentration experiment was done using a General Linear Model (GLM), including the initial prey concentration as predictor. Differences between SF and LF linear regressions of ingestion rates were tested with ANOVA test. Mann-Whitney-Wilcoxon test was performed to identify significant differences of ingestion rate between treatments in 
226

227

228

229

230

231

232

233

234

235

236

237

238

239

240

241

242

243

244

245

246

247

248

249

250

selectivity experiments. All statistical analysis was performed using the software R 3.1.1 (The R Project for Statistical Computing 2014) and taking $\alpha<0.05$ as the limit for statistical significance.

\section{Results}

Predation activity was systematically observed during the feeding experiments and occurred irrespective of $S$. aurata size class, the type of prey provided, and the tank. Furthermore, in several treatments, all the provided prey was consumed within the two hours of experiment, indicating the suitability of the experiment time.

\subsection{Monospecific diets experiments}

Predation activity on dry pellets (i.e. control) was consistently observed in all experiments and occurred for both size classes of $S$. aurata, showing the suitability of this type of food as control.

Both size classes displayed predatory activity over both benthic and pelagic stages of Aurelia sp. life cycle (Fig. 1). Large medusae were not totally consumed by any size class of fish, but bites on the edge of umbrellas were consistently observed. In these cases though, the biomass of Aurelia sp. consumed by the fish was not quantifiable with our protocol.

Ingestion rates for monospecific diets varied significantly according to the type of prey offered, both for the SF (Kruskal-Wallis test, $p<0.01$ ) and for the LF (KruskalWallis test,,$p<0.01$ ). Significant differences (Kruskal-Wallis test, $p<0.05$ ) were observed between the two size classes of $S$. aurata. The highest mean ingestion rates for SF was obtained for small medusa $\left(0.15 \pm 0.03\right.$ prey item. $\mathrm{g}^{-1}$ fish. $\left.\mathrm{h}^{-1}\right)$, polyps $(0.14 \pm 0.07$ prey item. $\mathrm{g}^{-1}$ fish. $\left.\mathrm{h}^{-1}\right)$ and Artemia $\left(0.11 \pm 0.00\right.$ prey item. $\mathrm{g}^{-1}$ fish. $\left.\mathrm{h}^{-1}\right)$, while ephyrae 
$251\left(0.05 \pm 0.02\right.$ prey item. $\mathrm{g}^{-1}$ fish. $\left.\mathrm{h}^{-1}\right)$, medium $\left(0.003 \pm 0.001\right.$ prey item. $\mathrm{g}^{-1}$ fish. $\left.\mathrm{h}^{-1}\right)$ and large 252 medusa (no consumption) presented lower values (Fig. 1). The multiple comparison, 253 though revealed that only medium medusa and large medusa presented significant lower 254 values as control (Dunn post hoc test with Bonferroni correction, $p<0.0018$ ), while the 255 remaining were not significantly different. For LF, Artemia $(0.11 \pm 0.00$ prey item.g$256{ }^{1}$ fish. $\left.\mathrm{h}^{-1}\right)$ and small medusa $\left(0.07 \pm 0.00\right.$ prey item. $\mathrm{g}^{-1}$ fish. $\left.\mathrm{h}^{-1}\right)$ were the most consumed 257 preys, followed by polyps $\left(0.04 \pm 0.02\right.$ prey item. $\mathrm{g}^{-1}$ fish. $\left.\mathrm{h}^{-1}\right)$, ephyrae $(0.03 \pm 0.02$ prey 258 item. $\mathrm{g}^{-1}$ fish. $\left.\mathrm{h}^{-1}\right)$, medium $\left(0.001 \pm 0.001\right.$ prey item. $\mathrm{g}^{-1}$ fish. $\left.\mathrm{h}^{-1}\right)$ and large medusa (no consumption). Significant lower values than dry pellets were only revealed by large medusae (Dunn post hoc test with Bonferroni correction, $p<0.0018$ ) (Fig. 1). Fish predation on medium medusae of Aurelia sp. was limited, when considering the quantity of individuals consumed, irrespective of fish life stage (Fig. 1). However, when considering ingestion rates in terms of biomass, Aurelia sp. medusae of medium size (Ø $=4 \mathrm{~cm})$ proved to be at least as important as small ones as a source of food for $S$. aurata. Indeed, because one medusae of $4 \mathrm{~cm}$ bell diameter provides approximately the same wet weight of food (3.94 g) than 50 individuals with bell diameters of $1 \mathrm{~cm}(3.74$ g), ingestion rates in terms of biomass were in fine similar between the two size classes of Aurelia sp. medusae, irrespective of the fish size class (Dunn post hoc test, $p=0.46$; $p=0.36$, for SF and LF respectively). It is worth noticing that the ingestion of Aurelia sp. small and medium medusae was consistently higher (Kruskal-Wallis test $p<0.05$ ) in the SF fishes $\left(0.0112 \pm 0.002\right.$ and $0.0116 \pm 0.003 \mathrm{~g} \cdot \mathrm{g}^{-1}$ fish. $\mathrm{h}^{-1}$, respectively) than LF $\left(0.005 \pm 0.000\right.$ and $0.004 \pm 0.003 \mathrm{~g} \cdot \mathrm{g}^{-1}$ fish. $\mathrm{h}^{-1}$, respectively), suggesting different food preferences for this species according to the size class. 


\subsection{Gradient of concentration experiments}

The results of ingestion rate obtained from the gradient of concentrations experiment suggested that the predation of $S$. aurata on Aurelia sp. individuals in the wild could be proportional to their availability, at least for the small medusae (Fig. 2).

The ingestion rates increased with increasing concentration supply, for both size classes, showing a significant correlation $(p<0.01)$ and significant differences between the two size classes of fish $(p<0.01)$. They reach the maximum value of $0.15 \pm 0.03$ prey item. $\mathrm{g}^{-}$ ${ }^{1}$ fish. $^{-1}$ for SF and $0.07 \pm 0.00$ prey item. $\mathrm{g}^{-1}$ fish. $\mathrm{h}^{-1}$ for $\mathrm{LF}$, which represents the ingestion of all available prey in the tank.

\subsection{Selectivity experiments}

Selectivity experiments showed that the attractiveness of Aurelia sp. as a prey depended on both its life stage (benthic or pelagic) and that of the fish (SF or LF) (Fig. 3). Although the results indicate higher ingestion rates for Artemia in both diets for SF, significant differences were obtained only when provided together with polyps (Wilcoxon test, $p<0.05$ ). For LF, Artemia was significantly selected when compared with ephyrae (Wilcoxon test, $p<0.05$ ). In diet 2 , however, the reverse situation was observed with the polyps presenting higher ingestion values (Wilcoxon test, $p<0.05$ ), despite the high variability in polyp ingestion rates among replicate tanks.

\section{Discussion}

The trophic interaction between fish and Aurelia sp. was assessed and found novel insights on the so far underestimated role fish predation can have on jelly fish population size. It is here hypothesised that oportunistic fish species, such as $S$. aurata (Escalas et al., 2015; Pita et al., 2002), might take advantage of local peaks in Aurelia 
sp. densities to partially sustain their growth. This study provide evidences that jellyfish are not 'dead ends' of the food web, as they are actively predated when an alaternative prey is not available, thereby favouring alternative energy pathways in food webs.

Both size classes of $S$. aurata feed on all life stages of Aurelia sp. offered as prey. This predator is an opportunistic feeder which commonly adapts its diet to the food resources available in its environment (Pita et al., 2002; Wassefand Eisawy, 1985) and can therefore prey on Aurelia sp. during blooms events. In contrast with former descriptions of the feeding preferences of this species (Escalas et al., 2015; Pita et al., 2002), the results provide evidence of the active predation of $S$. aurata on jellyfish. In line with this, several species of Sparidae family have been reported as jellyfish consumers (Ates, 1988; Mianzan et al., 1996), stressing the aptness of $S$. aurata as jellyfish predator.

The ingestion rates of both size classes of $S$. aurata varied significantly according to the type of prey offered. Firstly, it is worth noticing the high consumption of polyps by the SF. In the wild, younger individuals of $S$. aurata prey mainly on epibenthic polychaetes, small fishes, crustaceans and gastropods (Escalas et al., 2015; Tancioni et al., 2003), but with a clear dominance on bivalves in some habitats (Pita et al., 2002). As the polyps of Aurelia sp. in the experiments were provided fixed on the shells of living bivalves (oyster and mussel), it is possible that the actual target of fish predation was the settling substrate, rather than on the polyps themselves. Anyhow, bivalves are commonly colonized by polyps in the wild and particularly in Thau lagoon (Marques et al., 2015b), where bivalves play a crucial role in the development of Aurelia sp. benthic population. For instance, on submersed metal structures, oysters represent $90.4 \%$ of the biofouling that is colonized by the polys of Aurelia sp. in Thau lagoon (Marques et al., 2015b). Therefore $S$. aurata probably has a non negligible 
impact on the benthic population of Aurelia sp. in this ecosystem, either by direct predation on its polyps or by indirect mortality when feeding on the bivalves.

With regard to the vulnerability of Aurelia sp. pelagic life stages the results revealed that the intensity of $S$. aurata predation depends on prey size range. That is, small medusa appeared to be preferred by both size classes, but more evident for SF of S. aurata, which showed ingestion rates as high as those observed with the control pelleted food or with live adult Artemia. In contrast, large medusae with 7-8 $\mathrm{cm}$ bell diameter were bitten but never fully consumed, while predation on medium sized medusae $(\varnothing 4 \mathrm{~cm})$ was intermediate. Large medusae are highly vulnerable to capture by fish because their size increases their visibility in the water column and they have low escape capacities (Houde, 2001), which favour their consumption by fish. The preference of $S$. aurata for the smallest pelagic stages of Aurelia sp. may be therefore linked to prey size, which is largely controlled by mouth size in this species (Goldan et al., 1997; Russo et al., 2007; Wassef and Eisawy, 1985). Still, fish bites were observed in the edge of large medusae umbrella, suggesting that the quality of prey is not the hamper factor of its ingestion. Although just partially consumed, large jellyfish may provide a potential source of food for $S$. aurata and in turn, its bites damage the umbrellas of this jellyfish, reducing their capability to swim and capture prey.

Results showed that the small medusa $(\varnothing 1 \mathrm{~cm})$ is the most consumed Aurelia sp. stage by $S$. aurata, however when considering the contributions according to prey biomass, both small and medium medusae appear suitable as food source, highlighting the vulnerability of Aurelia sp. early pelagic stages to fish predation. Indeed, Aurelia sp. within this size range are found from March to May in Thau lagoon (Bonnet et al, 2012), which matches the annual period for S. aurata individuals settlement in the 
lagoon, either as post larvae or as sub-adults (corresponding to SF and LF size range) after a few months of overwintering at sea (Crespi, 2002; Mercier et al., 2012).

The observed trophic interactions between $S$. aurata and Aurelia sp. has wide implications for the population dynamics of the two species as the results showed that increasing availability of Aurelia sp. medusae boosts ingestion rates of $S$. aurata. In the experiments the fishes were exposed to higher concentrations of medusae than the maximum abundance recorded in Thau lagoon $\left(3.30 \times 10^{-3}\right.$ ind. $\mathrm{L}^{-1}$,Marques et al., 2015a), but in most tanks all the prey available was totally consumed. This suggests that even higher ingestion rates can be achieved if higher abundance of jellyfish are encountered in the wild as previously reported for other ecosystems (e.g. $2.48 \times 10^{-1}$ ind. $\mathrm{L}^{-1}$ in Kertinge Nor, Denmark; Olesen et al., 1994). Such observations are in line with former empirical evidence of $S$. aurata behavior, which increase food intake when proteins and lipids levels in the diet provided are low (Santinha et al., 1999). Because Aurelia sp. medusae are mainly composed of water (ca. 96\%) and have very low nutritional value (Lucas, 1994), higher volumes of these organisms must be ingested to meet predators energetic requirements (Cardona et al., 2012). In addition, as revealed here by significant differences of ingestion rates between the two size classes of fishes, larger predators may have a bigger impact on jellyfish population, as their food requirements are superior and greater numbers of jellyfish must be consumed. Nevertheless, the digestion rates of jellyfish (Arai et al., 2003) suggest higher ingestion as predator guts are cleared faster when feeding on these prey. Therefore the hypothesis is raised that important amounts of Aurelia sp. medusae are consumed punctually by both size classes of $S$. aurata each spring, contributing to the population size of the species in the Thau lagoon. 
The intensity of trophic link however, is probably dependent on the relative

375 densities of the various preys available in the lagoon at that time of the year. Indeed, the results of the prey selectivity trial pointed out that jellyfish are not preferred by $S$. aurata individuals when a type of prey with higher nutritional quality is equally available in the tank. Although carbon concentration was not estimated and considering that prey abundance was equally determined according to their size, it is realistic to assume that crustaceans represent a much important input of carbon as prey than jellyfish. Similar results were reported for the threadsail filefish (Stephanolepis cirrhifer), which was shown to preferentially ingest gelatinous prey when the high quality prey was less visible in the tanks (Miyajima et al., 2011). Likewise, prey accessibility was also pointed as a key factor in prey selectivity by $S$. aurata in the field (Pita et al., 2002). During bloom events, though, jellyfish dominance occurs as an outcome of their predation on zooplankton (Bonnet et al., 2012; Hansson et al., 2005; McNamara et al., 2013; Pereira et al., 2014; Purcell and Sturdevant, 2001), and can reduce the mesozooplankton stock by ca. $81 \%$, as reported in Thau lagoon (Bonnet et al., 2012). Such shifting from high energetically zooplankton community to low quality jellyfish dominating system, might promote an adjustment of prey selectivity of $S$. aurata favouring the most abundate prey item, i.e. jellyfish. Jellyfish energy content also increases during the period of gonad maturation (Milisenda et al., 2014), which, in Thau lagoon, occurs from April to June (Bonnet et al., 2012). Hence, given the high ingestion rates that were observed for this life stage in the present study, massive concentrations of jellyfish during blooms have been suggested to satisfy fish energy requirements within a very small area, thereby minimizing energy waste in foraging and prey capture (Cardona et al., 2012; Mianzan et al., 1996). 
The results suggest that jellyfish like Aurelia sp. can be a non-negligible source of food for opportunistic fish species, which has important implications on energy fluxes within food webs and on the population dynamics of both the jellyfish prey and their predators. Furthermore, these laboratory experiments revealed that Sparus aurata could prey on benthic (by direct or/and indirect predation) and pelagic stages of Aurelia sp., which might have an important impact on Aurelia sp. by increasing its predation rates, when the availability of prey with higher nutritional quality is reduced in the wild. These results offer insights on two important issues on jellyfish ecology; that is, fish, especially the opportunistic species, at least partially contribute to control jelly fish blooms, through top-down regulations by preying on different stages of their life cycle. The exploitation and consequent reduction of fish stocks is not only depleting jelly fish food competitors but also releasing jellyfish from the predation pressure. Purcell and Arai (2001) and Arai (2005) stated that predation by a large number of fish species with broad diets is more ecologically important than the predation by the relatively few specialized fishes with primarily gelatinous diets. Hence, this provides support on the role overfishing has in promoting jellyfish outbreaks (Roux et al., 2013). Second, during bloom events jellyfish may provide an alternative source of food which might favour the more opportunistic fish species. The energy from the lower trophic levels might therefore be diverted to fish species with less commercial value. Such modification of the energy pathways within the food webs should be further explored, included in ecosystem based models and considered in management strategies. 


\section{References}

Arai, M.N., 2005. Predation on pelagic coelenterates: a review. J. Mar. Biol. Assoc. UK 85, 523-536. doi:10.1017/S0025315405011458

Arai, M.N., 1988. Interactions of fish and pelagic coelenterates. Can. J. Zool. 66, 19131927.

Arai, M.N., Welch, D.W., Dunsmuir, A.L., Jacobs, M.C., Ladouceur, A.R., 2003. Digestion of pelagic Ctenophora and Cnidaria by fish. Can. J. Fish. Aquat. Sci. 60, 825-829. doi:10.1139/F03-071

Ates, R.M.L., 1988. Medusivorous fishes, a review. Zool. Meded. Leiden 62, 29-42.

Audouin, J., 1962. La daurade de l'étang de Thau Chrysophrys aurata (LINNÉ). Rev. Trav. Inst. Péches marit. 26, 105-126.

Bonnet, D., Molinero, J.C., Schohn, T., Yahia, M.N.D., 2012. Seasonal changes in the population dynamics of Aurelia aurita in Thau lagoon. Cah. Biol. Mar. 53, 343347.

Brotz, L., Cheung, W.W.L., Kleisner, K., Pakhomov, E., Pauly, D., 2012. Increasing jellyfish populations: trends in Large Marine Ecosystems. Hydrobiologia 690, $3-$ 20. doi:10.1007/s10750-012-1039-7

Cardona, L., Álvarez de Quevedo, I., Borrell, A., Aguilar, A., 2012. Massive consumption of gelatinous plankton by Mediterranean apex predators. PLoS One 7, e31329. doi:10.1371/journal.pone.0031329

Crespi, V., 2002. Recent evolution of the fishing exploitation in the Thau lagoon, France. Fish. Manag. Ecol. 9, 19-29.

Doyle, T.K., Houghton, J.D.R., McDevitt, R., Davenport, J., Hays, G.C., 2007. The 

energy density of jellyfish: Estimates from bomb-calorimetry and proximatecomposition. J. Exp. Mar. Bio. Ecol. 343, 239-252. doi:10.1016/j.jembe.2006.12.010

Escalas, A., Ferraton, F., Paillon, C., Vidy, G., Carcaillet, F., Salen-Picard, C., Le Loc'h, F., Richard, P., Darnaude, A.M., 2015. Spatial variations in dietary organic matter sources modulate the size and condition of fish juveniles in temperate lagoon nursery sites. Estuar. Coast. Shelf Sci. 152, 78-90. doi:10.1016/j.ecss.2014.11.021

Feidantsis, K., Pörtner, H.O., Lazou, A., Kostoglou, B., Michaelidis, B., 2009. Metabolic and molecular stress responses of the gilthead seabream Sparus aurata during long-term exposure to increasing temperatures. Mar. Biol. 156, 797-809. doi:10.1007/s00227-009-1135-Z

Goldan, O., Popper, D., Karplus, I., 1997. Management of size variation in juvenile gilthead . I : Particle size and frequency of feeding dry and live food. Aquaculture $152,181-190$.

Hansson, L., Moeslund, O., Kiørboe, T., Riisgård, H., 2005. Clearance rates of jelly fish and their potential predation impact on zooplankton and fish larvae in a neritic ecosystem (Limfjorden, Denmark). Mar. Ecol. Prog. Ser. 304, 117-131. doi:10.3354/meps304117

Houde, E.D., 2001. Fish larvae. Encycl. Ocean Sci. Vol. 2.

Ishii, H., Kojima, S., Tanaka, Y., 2004. Survivorship and production of Aurelia aurita ephyrae in the innermost part of Tokyo Bay, Japan. Plankt. Benthos Res. 51, 2635.

Lucas, C.H., 2001. Reproduction and life history strategies of the common jellyfish, 
Aurelia aurita, in relation to its ambient environment. Hydrobiologia 451, 229246.

Lucas, C.H., 1994. Biochemical composition of Aurelia aurita in relation to age and sexual maturity. J. Exp. Mar. Bio. Ecol. 183, 179-192.

Lynam, C.P., Gibbons, M.J., Axelsen, B.E., Sparks, C. A. J., Coetzee, J., Heywood, B.G., Brierley, A.S., 2006. Jellyfish overtake fish in a heavily fished ecosystem. Curr. Biol. 16, R492-3. doi:10.1016/j.cub.2006.06.018

Marques, R., Albouy-Boyer, S., Delpy, F., Carré, C., Le Floc'H, É., Roques, C., Molinero, J.-C., Bonnet, D., 2015a. Pelagic population dynamics of Aurelia sp. in French Mediterranean lagoons. J. Plankton Res. 0, 1-17. doi:10.1093/plankt/fbv059

Marques, R., Cantou, M., Soriano, S., Molinero, J.-C., Bonnet, D., 2015b. Mapping distribution and habitats of Aurelia sp. polyps in Thau lagoon, north-western Mediterranean Sea (France). Mar. Biol. 162, 1441-1449. doi:10.1007/s00227-015$2680-2$

McNamara, M.E., Lonsdale, D.J., Cerrato, R.M., 2013. Top-down control of mesozooplankton by adult Mnemiopsis leidyi influences microplankton abundance and composition enhancing prey conditions for larval ctenophores. Estuar. Coast. Shelf Sci. 133, 2-10. doi:10.1016/j.ecss.2013.04.019

Mercier, L., Mouillot, D., Bruguier, O., Vigliola, L., Darnaude, A., 2012. Multi-element otolith fingerprints unravel sea-lagoon lifetime migrations of gilthead sea bream Sparus aurata. Mar. Ecol. Prog. Ser. 444, 175-194. doi:10.3354/meps09444

Mianzan, H.W., Mari, N., Prenski, B., Sanchez, F., 1996. Fish predation on neritic ctenophores from the Argentine continental shelf: A neglected food resource? Fish. 
Res. 27, 69-79. doi:10.1016/0165-7836(95)00459-9

Milisenda, G., Rosa, S., Fuentes, V.L., Boero, F., Guglielmo, L., Purcell, J.E., Piraino, S., 2014. Jellyfish as prey: frequency of predation and selective foraging of Boops boops (Vertebrata, Actinopterygii) on the mauve stinger Pelagia noctiluca (Cnidaria, Scyphozoa). PLoS One 9, e94600. doi:10.1371/journal.pone.0094600

Miyajima, Y., Masuda, R., Yamashita, Y., 2011. Feeding preference of threadsail filefish Stephanolepis cirrhifer on moon jellyfish and lobworm in the laboratory. Plankt. Benthos Res. 6, 12-17.

Moretti, A., Fernandez-Criado, M.P., Cittolin, G., Guidastri, R., 1999. Manual on Hatchery Production of Seabass and Gilthead Seabream, Volume 1, Organization.

Olesen, N.J., Frandsen, K., Riisgard, H.U., 1994. Population dynamics , growth and energetics of jellyfish Aurelia aurita in a shallow fjord. Mar. Ecol. Prog. Ser. 105, $9-18$.

Pauly, D., Graham, W., Libralato, S., Morissette, L., Deng Palomares, M.L., 2009. Jellyfish in ecosystems, online databases, and ecosystem models. Hydrobiologia 616, 67-85. doi:10.1007/s10750-008-9583-x

Pereira, R., Teodósio, M.A., Garrido, S., 2014. An experimental study of Aurelia aurita feeding behaviour: Inference of the potential predation impact on a temperate estuarine nursery area. Estuar. Coast. Shelf Sci. 146, 102-110. doi:10.1016/j.ecss.2014.05.026

Pita, C., Gamito, S., Erzini, K., 2002. Feeding habits of the gilthead seabream (Sparus aurata) from the Ria Formosa (southern Portugal) as compared to the black seabream (Spondyliosoma cantharus) and the annular seabream (Diplodus annularis). J. Appl. Ichthyol. 18, 81-86. doi:10.1046/j.1439-0426.2002.00336.x 
Purcell, J.E., Sturdevant, M., 2001. Prey selection and dietary overlap among zooplanktivorous jellyfish and juvenile fishes in Prince William Sound, Alaska. Mar. Ecol. Prog. Ser. 210, 67-83. doi:10.3354/meps210067

Purcell, J.E., Uye, S., Lo, W., 2007. Anthropogenic causes of jelly fish blooms and their direct consequences for humans: a review. Mar. Ecol. Prog. Ser. 350, 153-174. doi:10.3354/meps07093

Purcell, J.E., 2012. Jellyfish and Ctenophore Blooms Coincide with Human Proliferations and Environmental Perturbations. Ann. Rev. Mar. Sci. 4, 209-235. doi:10.1146/annurev-marine-120709-142751

Purcell, J.E., 2005. Climate effects on formation of jelly fish and ctenophore blooms: a review. J. Mar. Biol. Assoc. UK 85, 461-476. doi:10.1017/S0025315405011409

Purcell, J.E., Arai, M.N., 2001. Interactions of pelagic cnidarians and ctenophores with fish : a review $27-44$.

Richardson, A.J., Bakun, A., Hays, G.C., Gibbons, M.J., 2009. The jellyfish joyride: causes, consequences and management responses to a more gelatinous future. Trends Ecol. Evol. 24, 312-22. doi:10.1016/j.tree.2009.01.010

Roux, J.-P., van der Lingen, C.D., Gibbons, M.J., Moroff, N.E.,Shannon, L.J., Smith, A.D.M., Cury, P.M., 2013. Jellyfication of marine ecosystems as a likely consequence of overfishing small pelagic fishes: lessons from the Benguela. B. Mar. Sci. 89(1): 249-284. doi: dx.doi.org/10.5343/bms.2011.1145

Russo, T., Costa, C., Cataudella, S., 2007. Correspondence between shape and feeding habit changes throughout ontogeny of gilthead sea bream Sparus aurata L., 1758. J. Fish Biol. 71, 629-656. doi:10.1111/j.1095-8649.2007.01528.x 
541 Santinha, P.J.M., Medale, F., Corraze, G., Gomes, E.F.S., 1999. Effects of the dietary 542 protein : lipid ratio on growth and nutrient utilization in gilthead seabream (Sparus 543 aurata L.). Aquac. Nutr. 5, 147-156.

544 Takao, M., Okawachi, H., Uye, S., 2014. Natural predators of polyps of Aurelia aurita 545 s.l. (Cnidaria: Scyphozoa: Semaeostomeae) and their predation rates. Plankt. Benthos Res. 9, 105-113.

547

Tancioni, L., Mariani, S., Maccaroni, A., Mariani, A., Massa, F., Scardi, M., 548 Cataudella, S., 2003. Locality-specific variation in the feeding of Sparus aurata L.: evidence from two Mediterranean lagoon systems. Estuar. Coast. Shelf Sci. 57, 469-474. doi:10.1016/S0272-7714(02)00376-1

551

552

553

554

555

556

557

558

559

560

561 
564 (PI: D. Bonnet). Authors are grateful to many colleagues from IFREMER Palavas for

565 their support during laboratory experiments. Authors are also grateful to the anonymous 566 reviwers for their valuable comments.

567

568

569

570

571

572

573

574

575

576

577

578 
581

582

596

597

598

599

600

601

602

Fig. 1: Mean ingestion rates (in number of prey item) observed in SF (top) and LF (bottom) of $S$. aurata for all prey types during the monospecific diets experiments. Error bars represent standard deviations in each case. Letters indicate significant differences between groups after Bonferroni correction $(p<0.0018)$. Note that the initial number of prey item offered $(n)$ varied according to prey type (for more details, refer to Table 1).

Fig. 2: Mean ingestion rates (in number of prey items) observed for SF and LF of $S$. aurata for increasing initial abundances $(n)$ of small medusae $(\varnothing=1 \mathrm{~cm})$ of Aurelia sp. in the tanks. Error bars represent standard deviations in each case.

Fig. 3: Mean ingestion rates (in number of prey items) observed in SF (top) and LF (bottom) of $S$. aurata for the various types of live prey (Artemia and ephyrae or polyps of Aurelia sp.) included in the two mixed diets used for the prey selectivity experiments. Error bars represent standard deviations in each case. Symbols above horizontal bars indicate when differences among groups were significant (*) or not (ns) at the risk level $\alpha=0.05$.

5

6

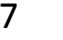

8


603 Table 1: Initial concentration of prey $\left(\operatorname{tank}^{-1}\right.$ and $\left.\mathrm{L}^{-1}\right)$ provided in the tanks during the different experiments, for SF and LF. Concentration of

\begin{tabular}{|c|c|c|c|c|c|}
\hline \multirow{2}{*}{ Experiment } & \multirow{2}{*}{ Prey type } & \multicolumn{2}{|c|}{$\begin{array}{c}\text { SF } \\
(n=3 \text { per tank })\end{array}$} & \multicolumn{2}{|c|}{$\begin{array}{c}\text { LF } \\
(n=2 \text { per tank })\end{array}$} \\
\hline & & prey item.tank ${ }^{-1}$ & prey item. $\mathrm{L}^{-1}$ & prey item.tank ${ }^{-1}$ & prey item. $\mathrm{L}^{-1}$ \\
\hline \multirow[t]{7}{*}{ Monospecific diets } & Dry pellets & 44 & 1.10 & 80 & 2.00 \\
\hline & Artemia & 44 & 1.10 & 80 & 2.00 \\
\hline & Polyps* & 390 & 9.75 & 448 & 11.20 \\
\hline & Ephyrae & 44 & 1.10 & 80 & 2.00 \\
\hline & Small Medusae (Ø1cm) & 50 & 1.25 & 50 & 1.25 \\
\hline & Medium Medusae $(\varnothing 4 \mathrm{~cm})$ & 1 & 0.03 & 1 & 0.03 \\
\hline & Large Medusae (Ø7-8cm) & 1 & 0.03 & 1 & 0.03 \\
\hline \multirow[t]{6}{*}{ Gradient of concentration } & Medusae $(\varnothing 1 \mathrm{~cm})$ & 5 & 0.13 & 5 & 0.13 \\
\hline & Medusae (Ø1cm) & 10 & 0.25 & 10 & 0.25 \\
\hline & Medusae (Ø1cm) & 15 & 0.38 & 15 & 0.38 \\
\hline & Medusae (Ø1cm) & 30 & 0.75 & 30 & 0.75 \\
\hline & Medusae (Ø1cm) & 40 & 1.00 & 40 & 1.00 \\
\hline & Medusae (Ø1cm) & 50 & 1.25 & 50 & 1.25 \\
\hline \multirow[t]{2}{*}{ Selectivity } & Ephyrae + Artemia & $22+22$ & $0.55+0.55$ & $40+40$ & $1+1$ \\
\hline & Polyps* + Artemia & $215+22$ & $5.38+0.55$ & $400+40$ & $10+1$ \\
\hline
\end{tabular}



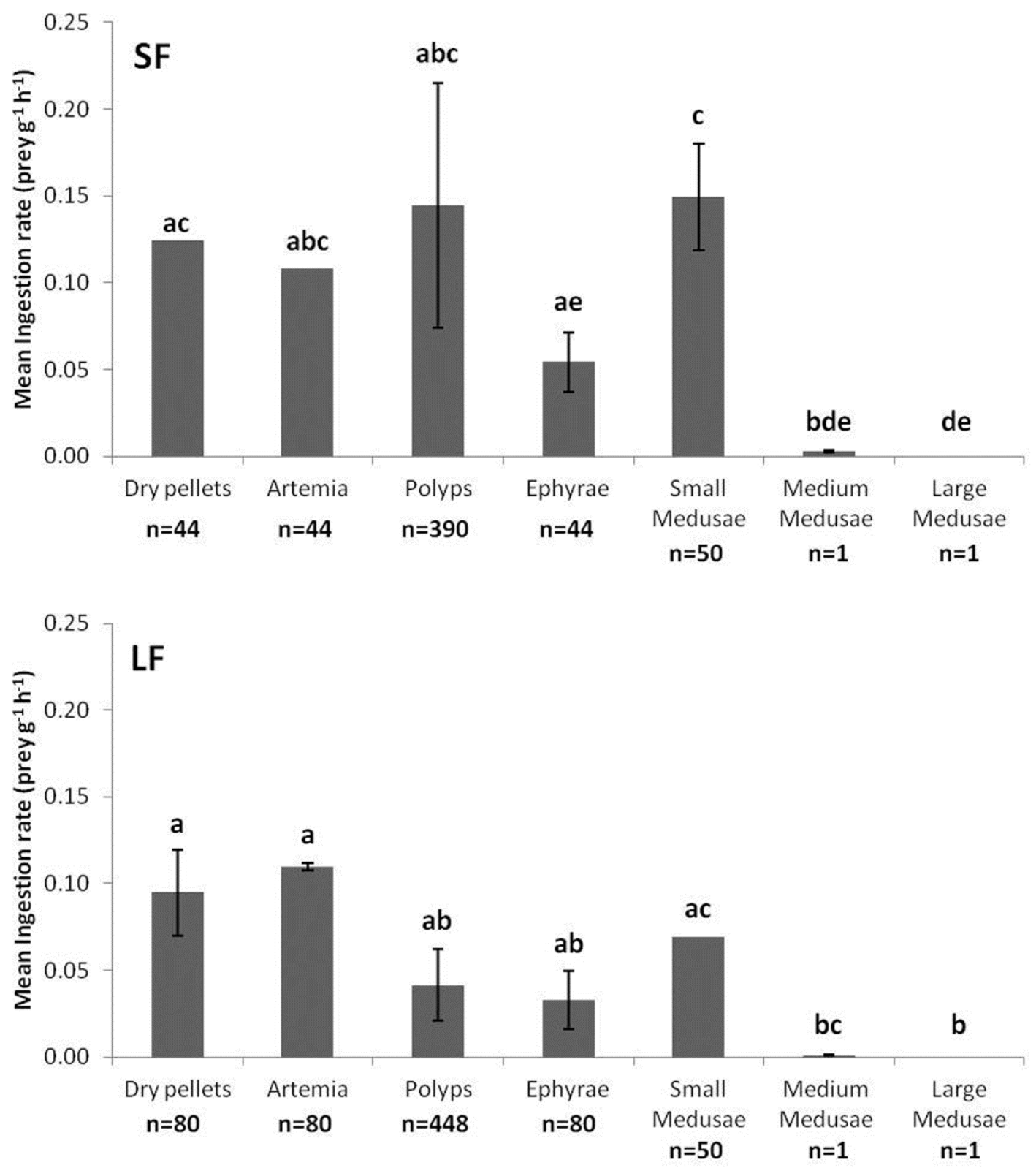

2 Fig. 1: Mean ingestion rates (in number of prey item) observed in SF (top) and LF

3 (bottom) S. aurata for all prey types during the monospecific diets experiments. Error

4 bars represent standard deviations in each case. Letters indicate significant differences

5 between groups after Bonferroni correction $(p<0.0018)$. Note that the initial number of

6 prey item offered $(n)$ varied according to prey type (for more details, refer to Table 1). 


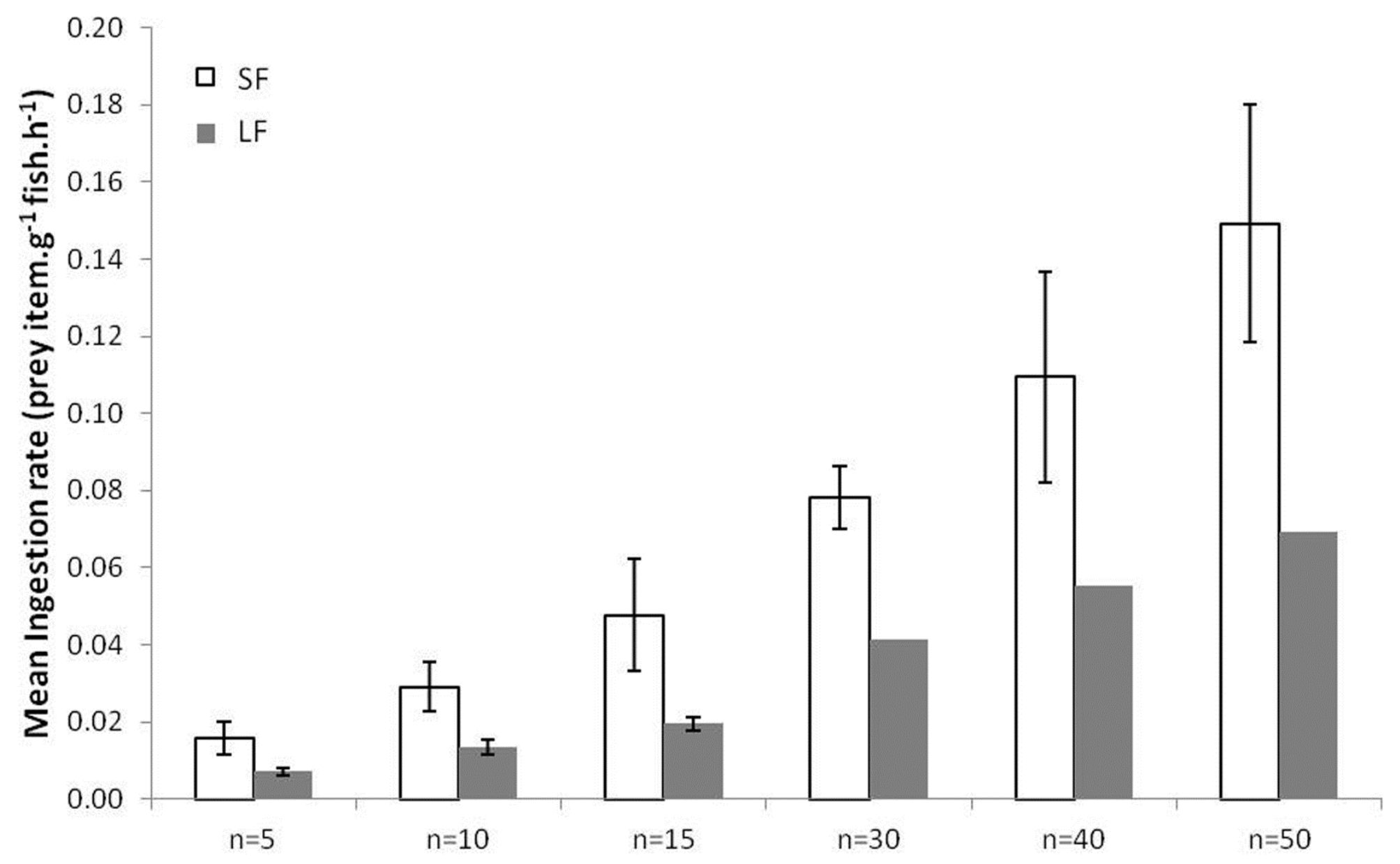

8 Fig. 2: Mean ingestion rates (in number of prey items) observed for SF and LF of $S$. aurata for increasing initial abundances ( $n$ ) of small 9 medusae $(\varnothing=1 \mathrm{~cm})$ of Aurelia $\mathrm{sp}$. in the tanks. Error bars represent standard deviations in each case. 

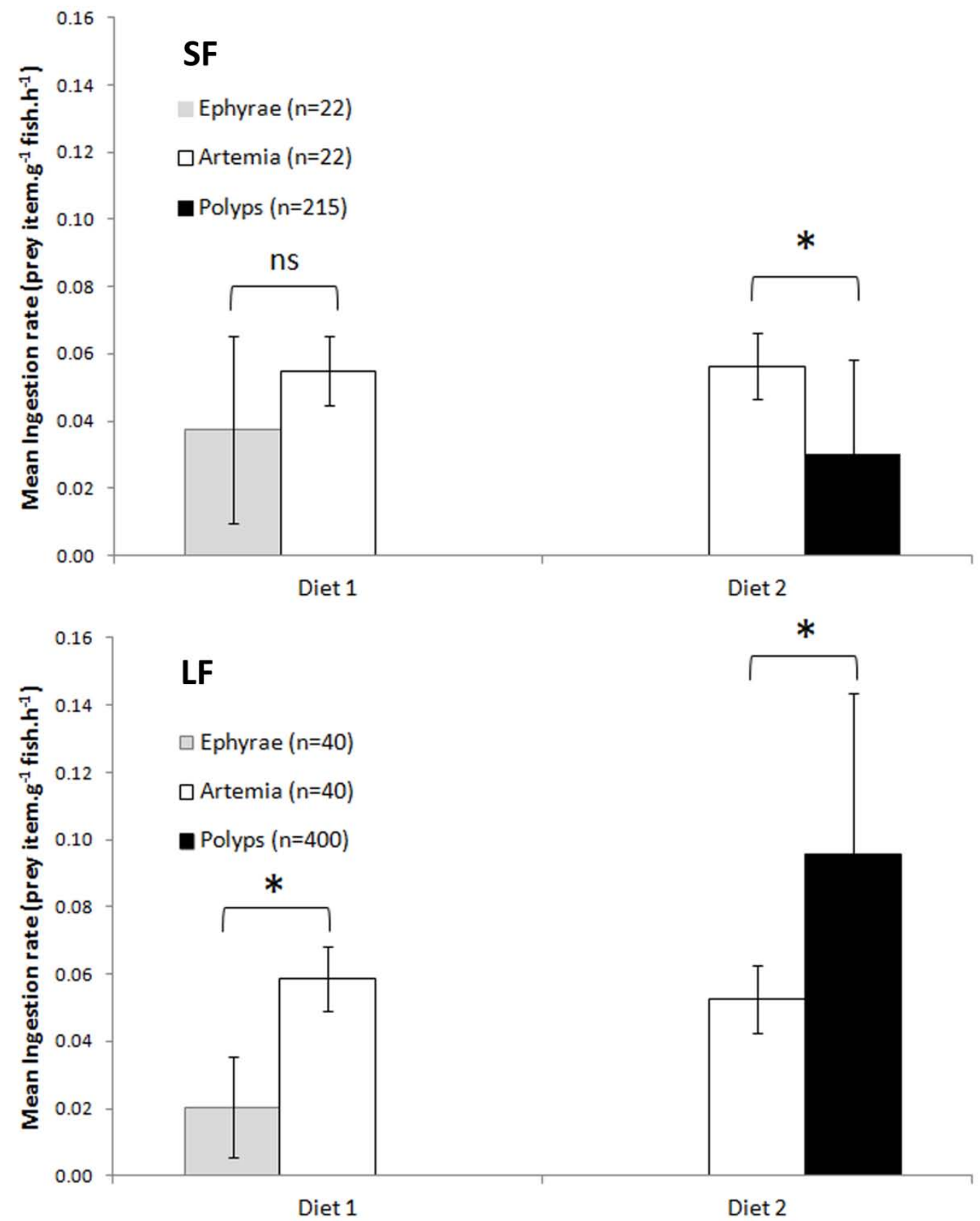

11 Fig. 3: Mean ingestion rates (in number of prey items) observed in SF (top) and LF

12 (bottom) of $S$. aurata for the various types of live prey (Artemia and ephyrae or polyps

13 of Aurelia sp.) included in the two mixed diets used for the prey selectivity experiments.

14 Error bars represent standard deviations in each case. Symbols above horizontal bars

15 indicate when differences among groups were significant $(*)$ or not (ns) at the risk level $\alpha=0.05$. 